\title{
PLANEJAMENTO ORCAMENTÁRIO E FINANCEIRO ATRAVÉS DAS PROGRAMAÇÕES NA ADMINISTRAÇÃO PÚBLICA
}

\author{
Miguelina Troisi Bonfrisco ${ }^{1}$ \\ Alexandre Pioner de Lima ${ }^{2}$
}

\section{Resumo}

Em decorrência da necessidade de garantir o cumprimento dos resultados fiscais e de obter maior controle sobre os gastos, a Administração Pública, em atendimento aos artigos $8^{\circ}$, $9^{\circ}$ e $13^{\circ}$ da Lei n. ${ }^{\circ} 101$ de 04 de maio de 2000, Lei de Responsabilidade Fiscal - LRF faz a programação orçamentária e financeira da execução das despesas públicas. A preocupação de manter o equilíbrio entre receitas e despesas no momento da execução orçamentária e financeira já constava na Lei n. ${ }^{\circ}$ 4.320, de 17 de março de 1964. Esse mecanismo determina a elaboração da programação financeira e do cronograma mensal de desembolso. A entrada das receitas que o governo arrecada dos contribuintes nem sempre coincide, no tempo, com as necessidades de realização de despesas públicas, por essa razão é que existe um conjunto de atividades que têm o objetivo de ajustar o ritmo da execução do orçamento ao fluxo provável de entrada de recursos financeiros que vão assegurar a realização dos programas anuais de trabalho e, consequentemente, impedir eventuais insuficiências de recursos financeiros. A esse conjunto de atividades chamamos de Programação Financeira.

Palavras-chave: Planejamento. Programações Financeiras - PF. SIAFI. Recursos Financeiros.

\footnotetext{
${ }^{1}$ Pós -Graduação em Administração Financeira. UNIASSELVI - Chefe do Serviço de Finanças do Hospital de Clínicas de Porto Alegre. mbonfrisco@ hcpa.edu.br

${ }^{2}$ Mestre em Administração. PUC-Rio - Administrador do Serviço de Orçamento do Hospital de Clínicas de Porto Alegre. aplima@ hcpa.edu.br
} 


\title{
BUDGET AND FINANCIAL PLANNING THROUGH FINANCIAL FORECASTS IN PUBLIC ADMINISTRATION
}

\begin{abstract}
Due to the need to ensure compliance with tax results and to obtain greater control over expenditures, the Public Administration, in compliance with articles 8, 9 and 13 of Law $\mathrm{n}^{\mathrm{o}} .101$ of May 4, 2000, Fiscal Responsibility Law - LRF makes the budgetary and financial programming of the execution of public expenditure. The concern to maintain the balance between income and expenditure at the time of budget and financial execution was already contained in Law $\mathrm{n}^{\circ} .4 .320$ of March 17, 1964. This mechanism determines the preparation of the financial programming and the monthly disbursement schedule. The inflow of revenues that the government collects from taxpayers does not always coincide, over time, with the need for public spending, for this reason there is a set of activities that aim to adjust the pace of budget execution to the likely inflow of financial resources that will ensure the realization of the annual work programs and thus prevent any shortfalls in financial resources. This set of activities we call Financial Forecasts.
\end{abstract}

Keywords: Planning. Financial Schedules - PF. SIAFI. Financial Resources.

\section{INTRODUÇÃO}

No passado a administração pública era vista de uma forma bastante peculiar, não eram utilizadas técnicas de administração, o governante determinava as ações e o interesse público era inexistente.

Com o passar dos anos a sociedade progrediu, surgiram novas perspectivas e houve profunda modificação na concepção social relativamente ao dever do administrador público. Esse processo trouxe a necessidade de se encarar a administração pública como um trabalho técnico a ser desenvolvido de forma planejada e normatizada. 
Buscando a aplicação de uma técnica previamente elaborada, descobriu-se que seria benéfico a importação de conceitos e métodos utilizados na administração privada, com as devidas adaptações.

$\mathrm{Na}$ atualidade, verifica-se que esta tendência de aplicar métodos que anteriormente eram exclusivos da iniciativa privada tem se mostrado como um caminho para a concretização dos princípios constitucionais aos quais estão subordinadas as ações da Administração Pública.

A elaboração de uma programação orçamentária e financeira requer muita habilidade e conhecimento técnico de orçamento, finanças e comportamento da arrecadação dos tributos federais que compõem a receita, bem como da estrutura do Estado. A programação financeira estará sempre submetida à vontade política do Governo, uma vez que o Orçamento é uma lei que autoriza a execução dos programas de trabalho nela contidos, isso significa que sua execução deve estar atrelada ao real ingresso de recursos, à medida que esses recursos vão ingressando nos cofres do Governo, são imediatamente liberados para os órgãos federais, baseado na programação financeira destes, para a execução dos seus programas de trabalho.

No presente trabalho a análise acerca do planejamento da atividade da Administração Pública será restrito ao planejamento orçamentário e financeiro através das programações, mediante a análise dos mecanismos disponíveis ao administrador e das exigências da legislação pertinente. Salienta-se que a questão do planejamento da Administração é muito mais ampla, ficando, porém, para uma próxima oportunidade, a análise de outros aspectos da gestão pública.

\section{PLANEJAMENTO}

O conceito de planejamento consiste no ato de criar e planejar, antecipadamente, uma ação, desenvolvendo assim, estratégias programadas para atingir determinado objetivo, está ligado à necessidade de se ter conhecimento prévio das atitudes a serem tomadas e das ações a serem desempenhadas. O planejamento é uma das mais importantes ferramentas de administração. É uma das principais etapas em qualquer processo de gestão, seja na entidade pública ou na empresa privada. 
Essa concepção também é aplicável à Administração Pública. Sem programação fica praticamente impossível a consecução dos objetivos pretendidos de forma satisfatória. Assim, é fundamental a elaboração de um plano que determine como se dará o processo de trabalho até que sejam alcançados os resultados finais.

O planejamento pressupõe estratégias, ou seja, o que se pretende atingir, tudo isso deve ser considerado. Na entidade pública essa premissa torna-se mais que fundamental, pois, além de ser uma determinação legal, trata-se de bem gerir os recursos públicos, por meio de uma gestão fiscal responsável.

Como salientado acima, o planejamento é uma exigência constitucional feita ao administrador público, prova disso são os vários dispositivos que demonstram a necessidade da elaboração de um plano para ação, cita-se como exemplo o art. 174 da Constituição da Republica Federativa do Brasil (1988): “Como agente normativo e regulador da atividade econômica, o Estado exercerá, na forma da lei, as funções de fiscalização, incentivo e planejamento, sendo este determinante para o setor público e indicativo para o setor privado".

A questão do planejamento está presente em diversas leis, as quais apresentam disposições, expressas ou não, acerca desse dever do administrador. A lei no 4.320/1964, que estabelece normas gerais para elaboração e controle dos orçamentos e balanços públicos, deixa clara a necessidade da Administração agir de forma planejada, há, inclusive, a exigência de que sejam realizadas análises específicas, baseadas em dados e estimativas para o futuro, para instrução das decisões a serem tomadas pelo administrador.

Outro dispositivo importante que exige planejamento é a Lei Complementar $\mathrm{n}^{\circ}$ 101/2000 (Lei de Responsabilidade Fiscal-LRF), há disposições exigindo ações planejadas por todo texto da lei. 


\subsection{O aspecto orçamentário}

O Orçamento Público é um dos instrumentos de gestão de maior relevância e provavelmente o mais antigo da administração pública, é um instrumento que os governos usam para organizar os seus recursos financeiros.

A Constituição Federal de 1988 delineou o modelo atual de ciclo orçamentário, instituindo três leis cuja iniciativa para proposição é exclusiva do Poder Executivo: Art. 165. Leis de iniciativa do Poder Executivo estabelecerão:

I - o plano plurianual

II - as diretrizes orçamentária

III - os orçamentos anuais.

$\S 1^{o}$ - A lei que instituir o plano plurianual estabelecerá, de forma regionalizada, as diretrizes, objetivos e metas da administração pública federal para as despesas de capital e outras delas decorrentes e para as relativas aos programas de duração continuada. (BRASIL, 1988).

Pode-se dizer que o Plano Plurianual - PPA é uma espécie de planejamento estratégico da Administração em virtude de projetar as ações da instituição em longo prazo. Com duração de quatro anos, o PPA é elaborado no primeiro ano do mandato do governante eleito, com vigência a partir do segundo ano de mandato. O projeto de Lei do PPA deverá ser enviado pelo Poder Executivo ao Congresso até quatro meses antes do encerramento do primeiro exercício financeiro do mandato do novo presidente, e devolvido para sanção até o encerramento da sessão legislativa.

O PPA servirá de base para a elaboração da Lei de Diretrizes Orçamentárias - LDO e para a Lei Orçamentária Anual - LOA.

Conforme mencionado, sua elaboração também está constitucionalmente prevista. $\S 2^{o}-A$ lei de diretrizes orçamentárias compreenderá as metas e prioridades da administração pública federal, incluindo as despesas de capital para o exercício financeiro subsequente, orientará a elaboração da lei orçamentária anual, disporá sobre as alterações na legislação tributária e estabelecerá a política de aplicação das agências financeiras oficiais de fomento. (BRASIL, 1988) 
A LDO orientará a elaboração orçamentária, compreendendo as prioridades e metas em consonância com o PPA, porém se referindo apenas ao exercício financeiro subsequente. Também deverá dispor sobre as alterações na legislação tributária, além de estabelecer a política das agências financeiras oficiais de fomento. O projeto de Lei da LDO deve ser encaminhado pelo Poder Executivo até oito meses antes do final do exercício financeiro e devolvido para sanção até o final do primeiro período da sessão legislativa.

Com a instituição da Lei de Responsabilidade Fiscal, a LDO incorporou novas atribuições associadas ao equilíbrio entre receitas e despesas que norteia todo o ciclo de alocação dos recursos públicos.

A Lei Orçamentária Anual - LOA compreende o orçamento fiscal, o orçamento da seguridade social, o orçamento de investimento das estatais. O projeto de Lei da LOA deverá ser enviado pelo Poder Executivo ao Congresso até quatro meses antes do final do exercício financeiro, e devolvido para a sanção até o encerramento da sessão legislativa.

$\mathrm{Na}$ LOA o valor a ser arrecadado (fruto de estimativa elaborada com base nos dados colhidos durante a elaboração da LDO) é subdividido em dotações com destinações específicas, cada dotação corresponde a uma despesa destinada a um órgão específico.

Deve haver, mais uma vez, planejamento, posto que devem ser calculados recursos suficientes para o custeio das despesas durante o exercício, haverá, inclusive, a chamada reserva de contingência, calculada com base na Receita Corrente Líquida, e destinada ao atendimento de situações emergenciais.

Durante a execução do orçamento, pode acontecer que as dotações inicialmente aprovadas na LOA sejam insuficientes para realização dos programas de trabalho, ou pode ocorrer a necessidade de realização de despesa não autorizada incialmente. Assim a LOA poderá ser alterada no decorrer da sua execução por meio de créditos adicionais, que são autorizações de despesa não computadas ou insuficientemente dotadas na LOA.

Os créditos adicionais classificam-se em: suplementares: são os destinados a reforço de dotação orçamentária já existente na LOA, especiais: os destinados a despesas para as 
quais não haja dotação orçamentária específica e os extraordinários: destinados a despesas urgentes e imprevistas, em caso de guerra ou calamidade pública.

O limite autorizado para abertura dos créditos deve estar prevista na LOA, em regra, orçamentos bem planejados utilizam pouco essa ferramenta. A excessiva abertura de créditos pode indicar falta de planejamento.

Em tempos de regime de gestão fiscal responsável, a Lei Complementar nº 101/2000 (LRF) exige ação planejada na Administração Pública (art. $1^{\circ}, \S 1^{\circ}$ ). O certo é que, quanto maior for o percentual autorizado na lei orçamentária em patamar acima da expectativa de inflação, maior será a evidência de falta de planejamento, organização e controle do ente da Federação; esses elementos são reveladores de uma gestão política inaceitável.

Essa falta de planejamento pode trazer diversos danos à Administração, assim é imprescindível que o administrador haja com responsabilidade, traçando um plano de atuação prévio para que seja evitada a tomada de decisões sem análise cautelosa.

\subsection{O aspecto financeiro}

A execução financeira representa o fluxo de recursos financeiros necessários à realização efetiva dos gastos dos recursos públicos para a realização dos programas de trabalho definidos, é necessário lembrar que recurso é dinheiro ou saldo de disponibilidade bancária (enfoque da execução financeira) e que crédito é dotação ou autorização de gasto ou sua descentralização (enfoque da execução orçamentária).

De acordo com a Lei 4.320/64 o exercício financeiro no Brasil é o espaço de tempo compreendido entre $1^{\circ}$ de janeiro e 31 de dezembro de cada ano, no qual a administração promove a execução orçamentária e demais fatos relacionados com as variações qualitativas e quantitativas que tocam os elementos patrimoniais da entidade ou órgão público Plano de Contas Aplicado ao Setor Público (PCASP).

O dispêndio de recursos financeiros oriundos do Orçamento Geral da União se faz exclusivamente por meio de Ordem Bancária - OB e da Conta Única do Governo Federal e se destina ao pagamento de compromissos, bem como a transferência de recursos entre as 
Unidades Gestoras, tais como liberação de recursos para fins de adiantamentos, suprimento de fundos, cota, repasse, sub-repasse e afins. A Ordem Bancária é, portanto, o único documento de transferência de recursos financeiros.

O ingresso de recursos se dá quando o contribuinte efetua o pagamento de seus tributos por meio de Documento de Arrecadação de Receitas Federais (DARF), junto à rede bancária, que deve efetuar o recolhimento dos recursos arrecadados, ao Banco Central do Brasil (BACEN), no prazo de um dia. Com o DARF Eletrônico e a Guia de Recolhimento da Previdência Social (GRPS) Eletrônica, os usuários do sistema podem efetuar o recolhimento dos tributos federais e contribuições previdenciárias diretamente à Conta Única, sem trânsito pela rede bancária.

Ao mesmo tempo, a Secretaria da Receita Federal recebe informações da receita bruta arrecadada, que é classificada a cada 10 dias no Sistema Integrado de Informações Financeiras (SIAFI). Esse valor classificado deve corresponder ao montante registrado no BACEN no período.

As instituições públicas federais, tendo recursos financeiros em caixa, começam a fase de saída desses recursos, para pagamentos diversos. O pagamento entre Unidades Gestoras ocorre mediante a transferência de limite de saque, que é a disponibilidade financeira da UG on-line, existente na Conta Única.

Para ter a disponibilidade em caixa (recursos financeiros) a Subsecretaria de Planejamento e Orçamento - SPO, Coordenação-Geral de Finanças, criou uma rotina de programações financeiras, esta rotina foi estabelecida em 2017, objetivando o adequado controle do fluxo financeiro às demandas por pagamento de programas e ações/políticas, bem como assegurar o cumprimento do disposto no Anexo II do Decreto de Programação Orçamentária e Financeira (Decreto n. ${ }^{\circ}$ 8.961, de 16 de janeiro de 2017), posteriormente detalhado na Portaria do Ministério da Fazenda n. ${ }^{\circ}$ 69, de 17 de fevereiro de 2017, a qual fixa o limite de pagamentos por órgãos do Poder Executivo Federal durante o exercício.

Tal programação deverá refletir a necessidade de recursos financeiros para efetuar os pagamentos a serem efetivados no mês subsequente. Os dados deverão ser preenchidos mensalmente por parte das Unidades Gestoras (UG), através de planilha padrão. 
O fluxo financeiro depende essencialmente das informações disponibilizadas por todas as áreas envolvidas nos processos de gestão do MEC.

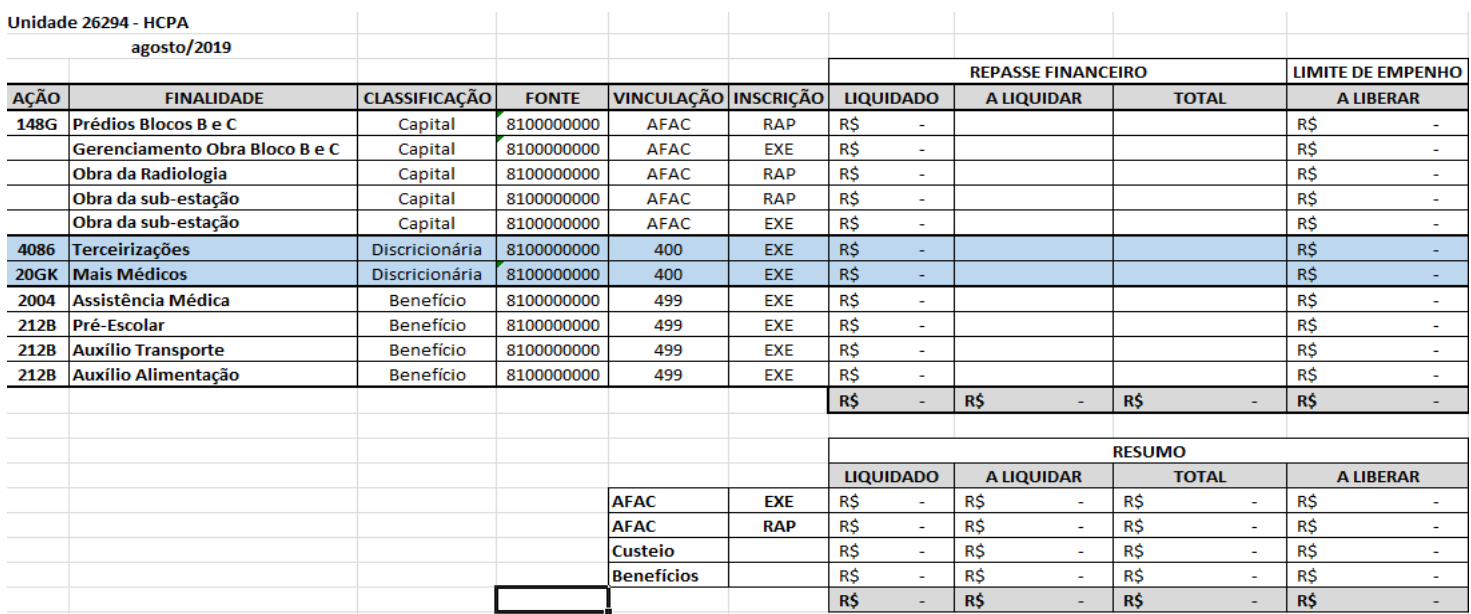

Figura 01. Planilha de Programação Financeira Mensal

Além da planilha de solicitação de recursos financeiros enviada mensalmente, a cada dia 20, onde consta a necessidade de pagamentos para o mês subsequente é necessária a emissão de uma Programação Financeira (PF) no SIAFI no início de cada mês.

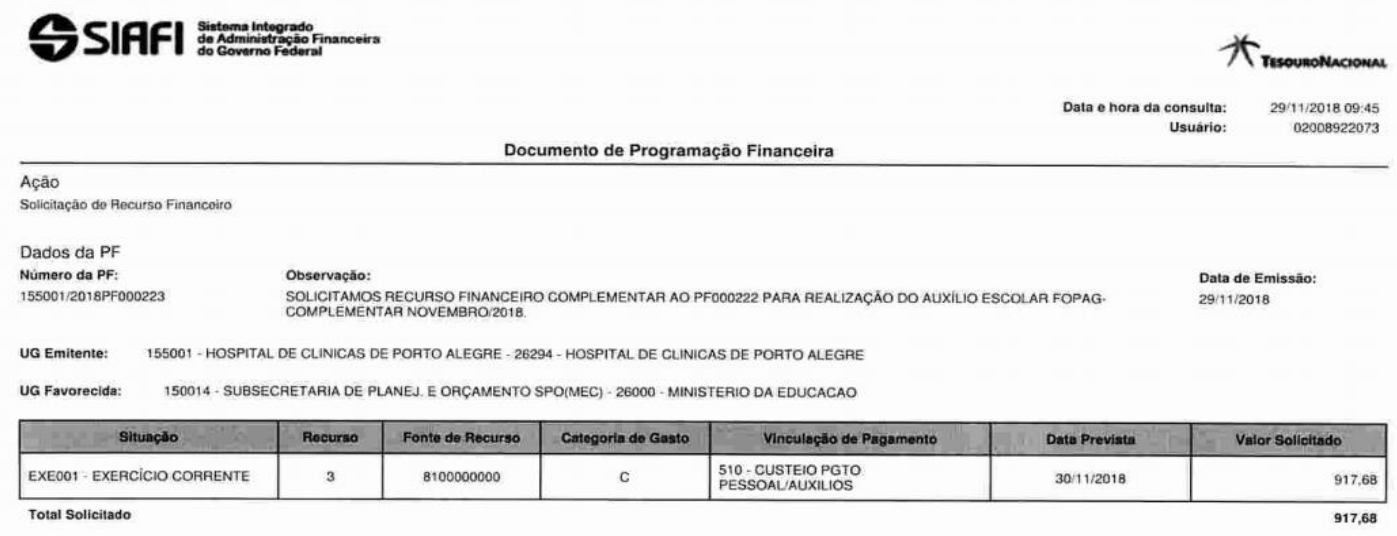

Criado por: 02008922073 - EVEUS COUTO SILVA|UG: 155001 - Data: 29/11/2018 as 09:45h

Figura 02. Tela de Programação Financeira (PF)

Esta programação e os controles financeiros estão vinculados ao Ministério da Fazenda. É através destas operações que o Governo Federal consegue organizar a disponibilidade de recursos entre todas as Unidades Gestoras. 


\section{CONSIDERAÇÕES FINAIS}

Sabe-se das infinitas demandas dos entes públicos, ao passo que os recursos para supri-las são escassos, diante disso, faz-se necessário o planejamento orçamentário e financeiro, que é o norteador das ações governamentais e é de suma importância para que haja equilíbrio nas contas públicas, é através dele que, após uma análise da real situação da unidade gestora, faz-se um direcionamento para utilização da verba.

Sendo assim, o planejamento orçamentário e financeiro possibilita a otimização dos recursos públicos o que é essencial para uma administração responsável. A falta de planejamento acarreta diversos problemas, tais como: ações emergenciais de custo elevado, obras paralisadas por falta de verba, empréstimos para cobrir despesas não previstas, além de diversos problemas contábeis que podem gerar sanções pessoais ao administrador público.

Com a realização deste trabalho foi possível concluir que o planejamento orçamentário e financeiro é uma ferramenta utilizada no âmbito da Administração Pública, embora não seja ao único a ser feito é através dele que se pode dizer que o Governo Federal consegue administrar os recursos financeiros de maneira mais eficaz.

Percebe-se também, que as exigências relativas ao planejamento das ações estão cada vez mais rígidas e cabe ao administrador cumpri-las. A tendência é que, em um curto espaço de tempo, já não haja mais espaço para leigos na Administração Pública. A técnica tem se sobreposto à política e o conhecimento sobre gestão pública tem se tornado indispensável. 


\section{REFERÊNCIAS}

BRASIL. Constituição da Republica Federativa do Brasil. Brasília, DF: Senado Federal, 1988.

BRASIL. Lei $n^{0}$ 4.320, de 17 de março de 1964. Brasília, DF. 1964. Disponível em: <http://www.planalto.gov.br/ccivil_03/leis/l4320.htm>. Acesso em julho de 2019.

BRASIL. Lei Complementar n⿳0101, de 4 de maio de 2000. Brasília, DF. 2000. Disponível em: $\langle$ http://www.planalto.gov.br/ccivil_03/leis/lcp/lcp101.htm $>$. Acesso em julho de 2019.

BRASIL. Lei 10.180, de 06 de fevereiro de 2001. Brasília, DF. 2001. Disponível em:<http://www.planalto.gov.br/ccivil_03/leis/leis_2001/110180.htm>. Acesso em julho de 2019.

HÜHNE, Leda Miranda. Metodologia científica. Agir : Rio de Janeiro, 1995.

MINISTÉRIO DA FAZENDA. Programação Financeira. Disponível em: $<$ http://www.tesouro.fazenda.gov.br/-/programacao-financeira $>$. Acesso em maio de 2019.

MINISTÉRIO DA FAZENDA. Manual do SIAFI. Disponível em: http://manualsiafi.tesouro.fazenda.gov.br/140000/140400/140443>. Acesso em maio de 2019.

MINISTÉRIO DA FAZENDA. Manuais. Disponível em: $<$ https://conteudo.tesouro.gov.br/manuais/index.php?option=com_content \&view=article\&id= 1539:020303-programacao-e-execucao-financeira\&catid=749\&Itemid=376>. Acesso em maio de 2019.

MINISTÉRIO DA FAZENDA. Manuais. Arquivos. Disponível em: $<$ http://www.cnmp.gov.br/intranet/images/stories/manuais_arquivos/pagamento\%20\%20final\%20abnt.pdf $>$. Acesso em maio de 2019.

ESCOLA NACIONAL DE ADMINISTRAÇÃO PÚBLICA - ENAP. Orçamento Público, conceitos básicos. Disponível em: http://repositorio.enap.gov.br/bitstream/1/2210/1/Or\%C3\%A7amento\%20P\%C3\%BAblico\% 20Conceitos\%20B\%C3\%A1sicos\%20-\%20M\%C3\%B3dulo\%20\%20\%285\%29.pdf.> Acesso em maio de 2019. 